\title{
A VOZ DA PERSONAGEM CRIANÇA E A ILUSTRAÇÃO: UM JOGO DE SILÊNCIOS
}

\author{
Bianca Rodrigues Cabral \\ Mestranda em Literatura pela Universidade de Brasília (UnB) \\ biancarodriguescabral@gmail.com
}

\section{RESUMO}

Este artigo discute sobre como nos livros infantis, bem como na arte em geral, ocorre a tensão entre o dito e o silêncio (não dito) e como a criança pode ganhar voz nesse entremeio. Utilizando como corpus a obra João por um fio (2005), escrito e ilustrado por Roger Mello, é analisado as possibilidades da hipótese criada por Cecília Bajour (2010), de que "a voz nasce do silêncio". Para tanto, partimos da premissa de que as linguagens presentes na literatura infantojuvenil, principalmente as ilustrações, marcam uma tentativa de dar voz ao protagonista-criança quando as palavras não são suficientes para tal tarefa. Como fundamentação teórica é utilizada a noção de alfabeto do silêncio (JUARROZ, 2001), de deslocamento de sentidos e linguagem das imagens (DIDIHUBERMAN, 1998), do silêncio também como barulho, e não como vazio (BRETON, 2006) e da literatura como criatura anfíbia (PAZ, 1993).

Palavras-chave: Literatura infantojuvenil, ilustrações, silêncio, voz da criança.

\section{ABSTRACT}

This article discusses how in children's books, as well as in art in general, the tension between said and silence (not said) occurs and how the child can gain a voice in this between. Using as a corpus the book João por um fio (2005), written and illustrated by Roger Mello, is possible analise the possibilities of the hypothesis created by Cecilia Bajour (2010), that "the voice is born of silence". Therefore, we start from the premise that the languages present in children's literature, especially the illustrations, mark an attempt to give voice to the protagonist-child when words are not enough for such a task. As a theoretical basis is used the notions of: the alphabet of silence (JUARROZ, 2001); the displacement of meanings and language of images (DIDI-HUBERMAN, 1998); silence as noise, not as emptiness (BRETON, 2006) and literature as an amphibian creature (PAZ, 1993).

Keywords: Children's literature, illustrations, silence, children's voice. 


\section{Introdução}

Uma das dificuldades nos estudos da literatura para crianças e jovens é pluralidade de formas que os livros podem assumir, tanto em questões textuais, já que não é classificada em "poemas", "romances", "ficção científica", como usualmente se adota nos livros adultos, quanto em questões materiais, já que assumem diferentes tamanhos, cores, texturas, dobras, etc. Essa dificuldade, na verdade, acaba sendo sua maior qualidade, pois dá liberdade aos executores do processo, ao autor, ao editor, e também ao leitor. Por esse motivo, muitas decisões são possíveis, inclusive de onde na página do livro será preenchido e onde não, onde teremos barulho e onde teremos silêncio.

No século XX, em que houve a pretensão de libertar a literatura infantojuvenil do vínculo didático e transformá-la em arte amadurecida, e assim inúmeras novas possibilidades surgiram, começou-se a refletir sobre o desenvolvimento do objeto-livro para crianças e jovens como sobrevivência em meio a vasta produção de bens culturais voltados à infância - desenhos animados, propagandas, brinquedos, jogos eletrônicos, filmes, etc. A literatura infantil passa então de um desafio para a criança pós-moderna para aliada. Integrando-se à realidade do leitor e à arte, a literatura infantojuvenil delineia seu maior traço: a liberdade.

Essa liberdade a torna também mais democrática, pois dessa forma e utilizando tantas linguagens, alcança diferentes tipos de pessoas, inclusive os que não são leitores ainda, ou as que não foram alfabetizados. Estes podem, por exemplo, compreender a história pelas ilustrações, ou pelos sons, ou pelo encarte, valorizando um projeto gráficoeditorial bem executado e absorvendo a história que mais lhe fizer sentido. "O texto, a 
imagem, os caracteres, a qualidade do papel, a encadernação coerente, a forma e o peso adequados à pequena mão do leitor farão do livro um todo que se verá prejudicado se uma das partes não for respeitada" (WORNICOV, p. 23, 1986). O livro infantojuvenil é um conjunto de linguagens que se falam, que em sua singularidade e em conjunto podem modificar a leitura: é um corpo plural e complexo. Isso faz dela uma obra de arte singular e única.

Pensando a partir disso, e guiados pelo texto "A voz nasce do silêncio", de Cecília Bajour (2010), temos como objetivo investigar como o silêncio, as pausas, os espaços em branco, se colocam em meio as linguagens que conversam na literatura infantojuvenil, para comprovarmos se é mesmo possível nascer uma voz desse silêncio. Em primeiro momento veremos como a arte e o projeto gráfico-editorial têm o poder de instalar pausas, que geram silêncios nas obras, e como isso interfere na leitura e na interpretação do espectador/leitor. Em segundo momento veremos como a língua, que é nosso maior suporte de comunicação, pode também nos calar, e como pessoas silenciadas, como as crianças, conseguem manobrar a língua para preencher os significados e ganhar voz, utilizando, por exemplo, a "linguagem das imagens". Em terceiro e último momento, antes das conclusões finais, colocaremos à prova a hipótese de que a voz pode nascer do silêncio, e de que, nesse sentido, a literatura infantojuvenil pode dar voz à criança e ao jovem mesmo que ela não narre sua história, mesmo que ela seja silenciada, observando as diferentes linguagens e recursos presentes na obra que utilizaremos como corpus, João por um fio (2005), escrito e ilustrado pelo brasileiro Roger Mello.

\section{Arte e o equilíbrio}


Calar. Mostrar pela metade. A arte se vale desse frágil equilíbrio entre o dito e o não dito. Na literatura podemos observar tal movimento, sobretudo na literatura infantil. Esse gênero se caracteriza por ter uma relação de interdependência entre imagens e palavras, que está presente não só no âmbito do que é dito ou mostrado, como também no livro como um todo, como objeto material e cultural. Como afirma Bajour, utilizando um exemplo de Hector A. Murena, em “La metáfora y lo sagrado" (2002), o estético, em meios literários, acontece quando "o silêncio é convocado já na palavra. Uma metáfora é pensá-lo na materialidade do livro: 'O traço negro de cada palavra se torna inteligível no livro a favor do branco da página. (...) A qualidade de qualquer escrito depende da medida em que se transmite esse mistério, esse silêncio'” (BAJOUR, p. 5, 2010). A interação das linguagens, a língua, a imagem e a edição constroem os sentidos em conjunto. É o todo que faz sentido. Embora os aspectos visuais comumente ganhem relevância, quando há a palavra ela não é somente um ornamento estético. Seria ingênuo pensá-la como algo óbvio que lhe rebaixa na hierarquia na hora da leitura, a palavra só não será importante quando ela não houver, em outros casos, todos os elementos do conjunto que formam um livro (que compõem o projeto gráfico-editorial) são importantes na mesma medida.

O que observamos é que esse conjunto de fatores que formam um livro se caracteriza também por buscar a hospitalidade do silêncio para, ali, compartilhar a palavra. A questão é qual parte desse silêncio pode interessar o leitor, e como se constrói essa narrativa silenciosa a qual a criança se identifica.

Não existe silêncio absoluto na linguagem artística, mas sim a possiblidade de contraste entre sons e silêncio, com imagens, palavras, movimentos e outros recursos possíveis. Porém, estamos acostumados a ler mais o que se diz do que se cala, como escreve o poeta Roberto Juarroz (2001): 
"Existe un alfabeto del silencio,

Pero no nos han enseñado a deletrearlo.

Sin embargo, la lectura del silêncio es la única durable,

Tal vez más que el lector"ii (JUARROZ, 2001, p. 28).

Aprender a soletrar o silêncio é um exercício difícil, já que não estamos acostumados, mas é de muita importância para a literatura infantojuvenil. Essa tarefa pode mudar a forma que vemos a palavra. Sabendo soletrar o silêncio, as palavras renascem com outras luzes, e vice-versa, já que as linguagens influenciam umas às outras.

\section{A linguagem, a criança e o silêncio}

As palavras são realmente importantes, tanto as ditas, quanto as não ditas. Elas são associadas à infância, pois é nesse período que o homem se apodera da linguagem, constituindo-se sujeito a partir dela. A infância (do latim infantia, do verbo fari $=$ falar, onde fan = falante e in constitui a negação do verbo), que etimologicamente é "ausência de fala". Percebe-se que a infância por si só é um momento silencioso em nossas vidas, pois passamos um grande tempo aprendendo como sonorizar ao mundo externo o nosso mundo interno.

Didi-Huberman (1998), ao discorrer sobre as imagens que as crianças constroem quando estão sozinhas, sendo parte do silêncio mesmo quando elas já são falantes, afirma que uma criança pode, por exemplo, se contentar em brincar com um lençol de cama. Um simples objeto da nossa vida prática, mas que pode se tornar um objeto passivo de representações e construções de outras imagens que não o de cobrir uma pessoa ou objeto. 
O teórico afirma que quando se subverte o sentido de lençol e ele vira um vestido ou uma tenda, por exemplo,

a transparência representativa - a equação do lençol e do sudário - se abre inteiramente, quero dizer que voa pelos ares ao mesmo tempo que passa para um registro semiótico bem mais amplo e mais essencial, que o supõe e a inclui: dialeticamente ela se realiza, na medida mesmo em que se abre aos deslocamentos de sentido pelos quais a superfície branca indeterminada será capaz de recolher feixe, impossível de conter, de sobredeterminações. E isto, sublinhemos, sem nada perder de sua essencial simplicidade material (DIDI-HUBERMAN, 1998, p. 87).

É, portanto, um trabalho de subversão de sentidos e significações das coisas o que a criança faz quando transforma em vestido um lençol, por exemplo. Ainda em consonância com Didi-Huberman, esse deslocamento de sentidos depois de uma vez feito é impossível conter a quantidade de outros que podem surgir, mesmo sem nada mudar o material, mesmo esse material sendo em sua essência simples, como um lençol branco.

Quando se torna capaz de abrir a cisão do que nos olha no que vemos, a superfície visual vira um pano, um pano de vestido ou então a parede de um quarto que se fecha sobre nós, nos cerca, nos foca, nos devora. Talvez só haja imagem a pensar radicalmente para além do princípio de superfície (DIDI-HUBERMAN, 1998, p. 87).

Esse movimento de "pensar além do princípio de superfície" é o que é feito na literatura infantil. O uso da "linguagem das imagens" é um ganho enorme para o desenho de como enxergamos hoje a literatura infantojuvenil. Essa linguagem é justamente o que caracteriza tais textos como literatura, que estimula a imaginação, que trabalha com metáforas e com as palavras de forma a evocar imagens, (não só no sentido literal e imediato de imagem) e conhecimento de mundo, faz da leitura um exercício. 
Poderíamos ver a literatura infantojuvenil, por causa disso, também como algo místico, já que é construído pela pelo subjetivo, que nos propicia alcançar epifanias, o divino. Não é ao acaso que a Bíblia, por exemplo, é repleta de metáfora. Jesus, supostamente, em suas pregações utilizava a "linguagem das imagens" e isso foi herdado nos escritos posteriores. Conhecer mais essa linguagem proporciona um melhor entendimento da Bíblia, em passagens como "Vós sois o sal da terra." (Mateus 5:13). Portanto, acredita-se ser o meio para chegar mais perto de Deus, do divino, o que em teoria a literatura infantojuvenil seria capaz de fazer. Talvez essa associação que tenha feito à imagem do senso comum da criança como "pura".

É saindo da superfície óbvia das palavras que as ilustrações, o projeto gráficoeditorial e o livro nos atingem, como se voltássemos ao estado de ausência de fala percebendo o mundo pela primeira vez, e criássemos várias imagens para um simples lençol, por exemplo. Criar imagens é uma forma de sair do silêncio, mesmo que no texto escrito isso não aconteça.

El silencio no es nunca el vacío, sino la respiración entre las palabras, el repliegue momentáneo que permite el fluir de los significados, el intercambio de miradas y emociones, el sopesar ya sea de las frases que se amontonan en los labios o el eco de su recepción, es el tacto que cede el uso de la palabra mediante una ligera inflexión de la voz, aprovechada de inmediato por el que espera el momento favorable. (BRETON, 2006, p. 14). ${ }^{\text {ii }}$

Principalmente quando nos referimos a arte, o silêncio nunca é o vazio. A arte, inclusive, ocupa o lugar do vazio, ela tenta dar voz a ele. "Ver o silêncio como vazio, como omissão, é deixar na linguagem - e somente na palavra - a possibilidade de ruído" 
(BAJOUR, p. 3, 2010). É aprendendo a observar os ruídos do silêncio que podemos valorizar, por exemplo, a voz das crianças na literatura.

\section{Quando o silêncio fala}

Como exemplo de exercício do enxergar o silêncio, vamos utilizar a obra João por um fio (2005), escrito e ilustrado pelo brasileiro Roger Mello. É uma obra em formato retangular $23 \times 15,5 \mathrm{~cm}$, de capa dura, que mostra o conflito de um menino, filho de pescador, quando chega a hora de dormir. A narrativa permeia o mundo simbólico dos sonhos, da imaginação, evidenciando que a noite pode ter significado de solidão, introspecção, para as crianças e, além disso, pode causar medo. É preciso uma leitura atenta para se perceber a voz da criança protagonista nessa obra, já que podemos dizer que conta duas histórias: uma nos textos e outra nas imagens, em que as duas se completam.

A narrativa se inicia com uma das poucas falas de João, o protagonista, revelando o seu sentimento quando se deita para dormir: "Antes de dormir o menino puxa a coberta: - Agora sou só eu comigo?" E depois disso a aventura do menino se inicia. As outras falas e quem narra o livro é provavelmente um adulto, onisciente, que tenta estimular João através de perguntas a contar a sua história, que será desenvolvida em outro fio narrativo, o das imagens. O livro é construído de forma que as perguntas feitas na linguagem escrita sugiram um silêncio, as pouquíssimas entradas do protagonista também sugerem um silêncio, o que supre esse vazio são as imagens, é nela que percebemos a voz da criança. "A figura silenciosa do narratário, um ouvinte mascarado, nasce do 'traço negro' do 'você', mas encarna o branco de uma ausência, a de alguém 
que não fala. Contudo, em sua escuta se sustenta o relato" (BAJOUR, p. 6, 2010). É por isso que devemos prestar atenção também nas outras linguagens da obra, que é onde o narratário silencioso não só reflete sua escuta e sustenta o relato, mas onde também fala.

Na primeira cena do livro, o narrador questiona "que tamanho é a colcha que cobre João, se é do tamanho da cama ou se é do tamanho da noite". Nas ilustrações, a colcha branca sobre o preto se destaca, mostrando uma enorme coberta, dando impressão ao leitor que ela não tem fim. Dessa forma, a sugestão da pergunta feita pelo leitor está contemplada na ilustração de forma indireta, mostrando uma colcha grande em relação à João, que parece pequeno ao se cobrir.

A história em silêncio, a voz da criança se passará nas tramas dessa colcha. Nela se pode ver a mistura da realidade com os sonhos, os medos, as aventuras, e uma série de sentimentos e referências. É nessa narração muda, porém falante que a criança ganha espaço, é no silêncio que a história maior se passa, já que existe pouco texto. É na sugestão, na percepção que se torna possível ler a história.

Figura 1 - Imagem 3: João por um fio, Mello, 2005 - Cena 2

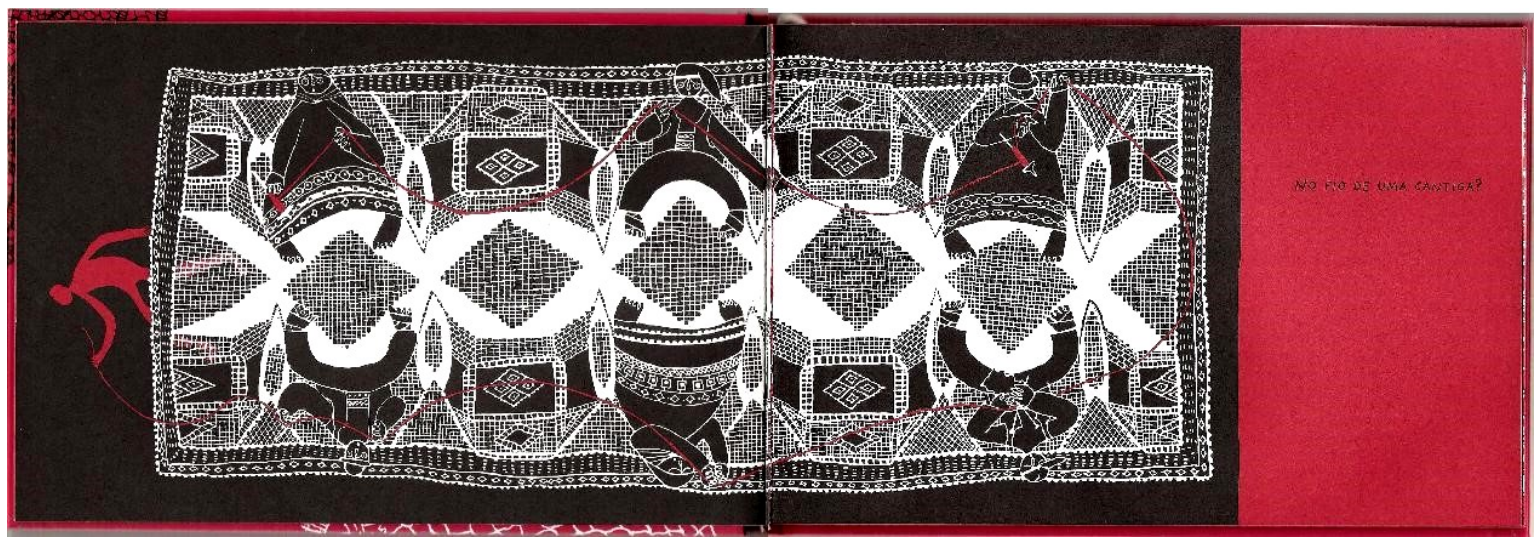

Fonte: Autora 
Na cena demonstrada pela imagem acima, João aparece segurando uma linha vermelha. Nesse momento ele ainda tem o controle sobre o que é tecido, sobre os acontecimentos. Na trama que o protagonista tece há homens e mulheres artesãos que compartilham do mesmo fio. No texto escrito a pergunta do narrador investiga o paradeiro da noite, o que podemos sugerir com as imagens é que ela pode estar escondida, que pode estar em coisas simples e significativas como nas cantigas, que os artesãos na vida real cantavam enquanto fiavam como um gesto de embalo.

Essa cena também nos remete às moiras da mitologia grega. Elas eram três irmãs que determinavam o destino tanto dos deuses, quanto dos seres humanos. Essas mulheres lúgubres são responsáveis por fabricar, tecer e cortar aquilo que seria o fio da vida de todos os indivíduos. O fio na imagem, que aparece tão vermelho quanto o sangue mais pulsante, se destacando do resto, e as pessoas tecendo o mesmo tecido, nessa leitura, seriam as moiras que tem o fio da vida de João nas mãos.

Essa brincadeira com a colcha nos remete ao que Didi-Huberman fala sobre o lençol. Em João por um fio vemos na prática o movimento de "pensar além do princípio de superfície", de pensar além do texto, inclusive além das ilustrações, e de construir um sentido dando voz à criança.

Continuando a narração o narrador sugere que a noite pode estar na "cordilheira de linhas que cobrem João", sendo essa cordilheira de linhas a própria colcha que mais uma vez predomina na página. Nessa cena João é levado pela cordilheira e chega ao outro lado da colcha. O movimento do menino também é sinalizado no texto escrito que diz que ele faz "brincadeira dos pés" que fazem "terremotos debaixo da colcha". Esse terremoto pode simbolizar a desordem dos pensamentos de João quando está com sono, mas ao mesmo tempo ainda tem controle da situação ao ser comparado com um gigante, 
quando no texto escrito aparece: “Quem tem medo de um gigante chamado João?" E nas rendas das tramas do menino aparece, quando olhamos atentamente, figuras humanas, se referenciando à civilizações que moram ao entorno de cordilheiras.

Figura 2 - Imagem 5: João por um fio, Mello, 2005 - Detalhes da cena 3

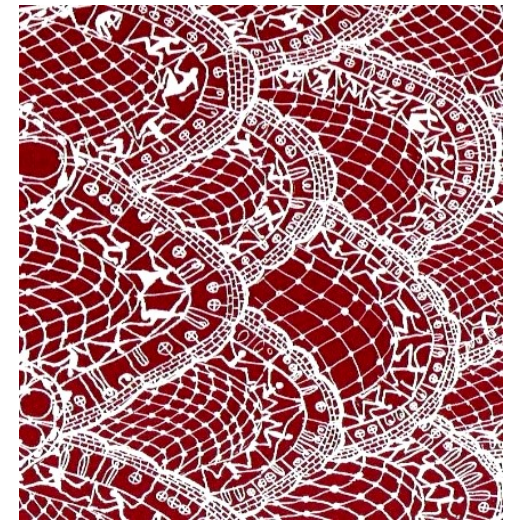

Fonte: Autora

Os detalhes da renda nas ilustrações nos lembram a renda Renascença, muito utilizada no nordeste brasileiro. A renda Renascença é uma técnica têxtil que teve sua origem em Veneza, na Itália, no século XVI, e foi introduzida no Brasil por freiras europeias. O bordado delicado difundiu-se pelas mãos das rendeiras nordestinas, virou uma tradição típica de arte que é passada de geração em geração. A colcha de retalhos, a renda renascença, a cultura da pesca, entre outras características que aparecem na obra literária, nos remetem à cultura nordestina brasileira, a tornando uma obra com elevadas riquezas culturais, além de escancarar o quão silenciadas nossas crianças são.

Depois de muito brincar com as imagens, João perde o controle e cai no sono. As ilustrações representam as águas e peixes, fazendo uma alusão ao pai que é pescador, continuando com a proposta de narração pela renda na colcha. Em seguida, há uma mudança de cenário: 
Figura 3 - Imagem 7: João por um fio, Mello, 2005 - Cena 4

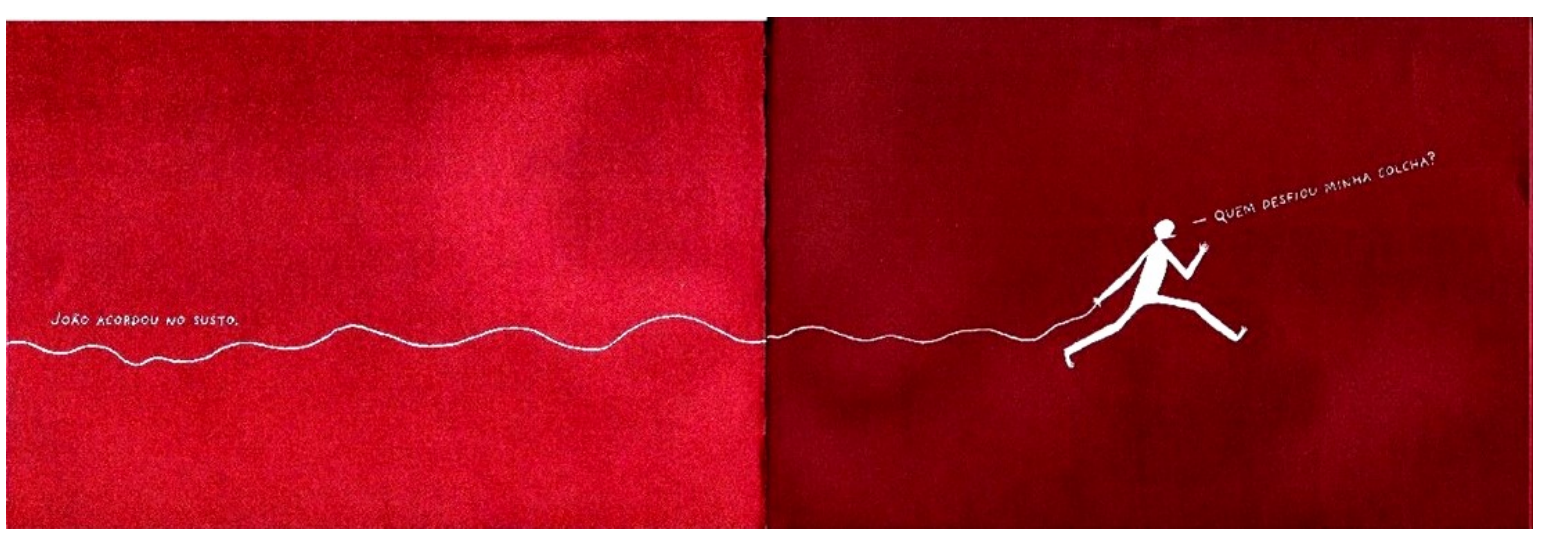

Fonte: Autora

Observamos na cena que a colcha desaparece, João acorda e puxa a linha branca que representa os restos da colcha. No lado esquerdo o texto escrito fala: "João acordou no susto", e do lado direito o menino pergunta: "Quem desfiou minha colcha?". A colcha que representa o sono, o sonho, também é proteção dos perigos que inventamos para a noite, e quando ela some João tem que buscar uma solução. Na cena seguinte há um vazio, nenhuma ilustração, somente o texto com a pergunta: "De que tamanho é o vazio onde antes estava a colcha que cobria João?". Aqui temos a inversão do silêncio, o vazio se mostra não no texto, mas na ausência de imagens. É a representação de que o silêncio é mesmo o jogo do ora dito, ora não dito, e que cabe ao leitor preenchê-lo de acordo com as pistas que o texto ou as ilustrações dão.

Depois disso João perde o sono e vê palavras espalhadas pelo quarto, e soluciona o problema refazendo a colcha a partir delas, como vemos na imagem abaixo. As palavras que ele tece são elementos de seu cotidiano, e que estão presentes na obra, tais como terremotos, peixe, rio, cidadezinha, vazio, rede, dormir, colchão, entre outras. Nesse momento vemos claramente que João tece sua própria história, com pedaços da realidade e pedaços do sonho, e faz sua nova colcha. Com as suas palavras, sua história, 
ele está protegido novamente e pode voltar a dormir, em um movimento cíclico de histórias, sugerido pelo texto escrito na última frase do livro: "De que tamanho é a colcha de palavras que cobre João?", nos remetendo a primeira pergunta feita pelo narrador. Além disso, a colcha que João tece é representada enormemente na página a ponto de não enxergarmos o fim, sugerindo o início de uma nova história.

Figura 4 - Imagem 8: João por um fio, Mello, 2005 - Cena 5

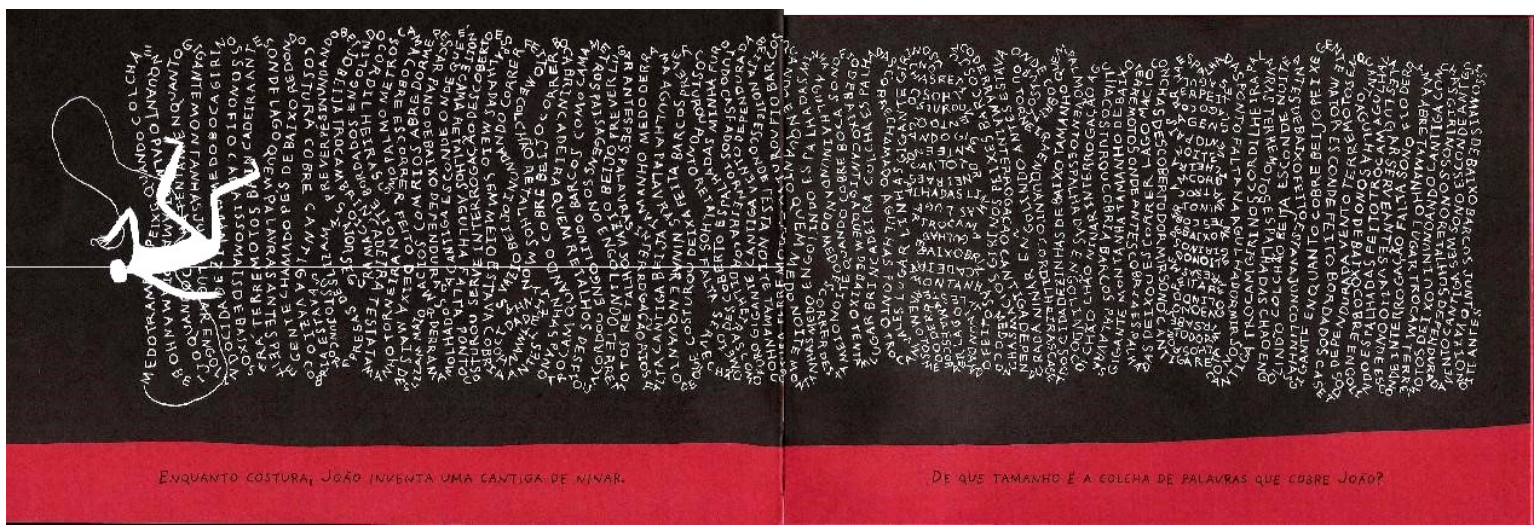

Fonte: Autora

É nessa última ilustração que o tecer e o narrar se fundem. Em português, utilizamos em literatura a palavra "enredar", que pode ser pensado, nesse caso, a junção de "enredo" com "rede" em forma de verbo, ação, que seria a costura. Aqui, a trama da literatura e a trama do tecido viram um só: a literatura. Nessa cena, como observada pela imagem, temos também uma grande subversão. Nela, as palavras que ilustram a imagem, e não o inverso, reforçando nossa ideia de que as imagens falam, inclusive literalmente como nesse momento. Este é também um grande exercício de pensarmos sobre a arte e sobre a literatura infantojuvenil em suas várias formas possíveis, e em como pode, de formas variadas, contar uma história e dar voz a seu público alvo. 


\section{Conclusões silenciosas}

Pode soar estranho falar em silêncio quando a palavra, a imagem ou a materialidade do livro falam tanto. Há casos, como o que vimos, em que se procura sempre ultrapassar o limite do possível, textos que constroem o não dito, ou o que é dito pela metade, por meio do jogo sutil entre a abertura do texto escrito e da ambiguidade da imagem. A partir do livro João por um fio utilizado como exemplo, podemos perceber que a busca pelo que não está, mas é sugerido, é uma premissa da arte e não poderia ser diferente com a literatura infantil. Quando falamos em literatura, o estético também acontece no silêncio que é evocado.

Octavio Paz se refere aos poemas-objetos como uma "Criatura anfíbia que vive entre dois elementos: o signo e a imagem, a arte visual e a arte verbal. Um poema objeto se contempla e, ao mesmo tempo, se lê ( $P A Z, 1993$, p. 22, tradução nossa), e também as define como sendo coisas "Mudas que falam. Vê-las é ouvi-las. O que dizem? Dizem advinhas, enigmas. Imediatamente esses enigmas se entreabrem e deixam escapar, como a crisálida e a mariposa, revelações instantâneas" (PAZ, 1993, p. 22, tradução nossa).

A literatura infantil se comporta como os poemas-objetos definidos por Octavio Paz. Ela também é uma "criatura anfíbia" que aos poucos vai se revelando, como pudemos ver na história do menino João. Além disso, a possibilidade de ter acesso ao personagem não só pelo viés escrito, mas também pelo ilustrativo, faz com que as personagens crianças tenham voz, já que são frequentemente silenciadas inclusive na própria literatura infantil. Quando João tece as palavras de sua história, podemos ver que sai do estado de ausência de fala e se apropria de sua voz, como uma epifania do que estava tentando falar o livro todo. Através de recursos como metáfora e metonímia, 
substituindo total ou parcialmente os sentidos, ludicamente se provoca a busca de uma possível resposta em quem aceita a arte de adivinhar, e aceitar essa possibilidade é legitimar vozes, é poder escutar, por exemplo, a voz de João.

"Expandir as fronteiras na tentativa de explorar as possibilidades do livro ilustrado nos aproxima do conceito de livro como jogo, que é talvez muito melhor por isso" (HUNT, 2010, p. 249). Esse jogo torna a leitura mais interessante para pessoas de todas as infâncias, ou se preferir, idades. A leitura das imagens da vida noturna e agitada mesmo que silenciosa do menino João não é fácil e de única interpretação, exige do leitor uma atenção e uma cumplicidade com o personagem para perceber os detalhes, assim como em qualquer outra obra do gênero, já que estamos tão distantes desse outro (criança) que um dia já fomos.

O sono traz insegurança e dela vem os temores, o temor da noite, e, portanto, do silêncio que muitas vezes desperta medo, e vemos isso na narrativa imagética. João procura distrair-se enquanto o sono não vem e brinca. O ilustrador usa traços finos para narrar os sonhos e os medos que preenchem a noite de sono do menino, e conhecer esse personagem e sua voz em seu mundo mudo, porém barulhento é tão encantador, que nos faz querer segurar a agulha dessa colcha de sonhos também, em todas as obras, incluindo a nossa própria. É possível dizermos que se tratando de literatura infantil, a narrativa verbal sugere uma maior, que se desenvolve pelas ilustrações, e são nelas que, em muitos casos, a criança antes silenciada ganha voz e movimento. João, portanto, que seria uma criança silenciada na fiç̧ão, e provavelmente realmente seja para muitos adultos que Ihe leem, na verdade só tem um jeito próprio de falar, que não é por palavras, mas por imagens, onde está em liberdade, onde nasce sua voz, meio ao silêncio. 


\section{Referências}

BAJOUR, Cecília. A voz nasce do silêncio. Revista Imaginária. n. 275. Disponível em: <http://imaginaria.com.ar/2010/07/la-voz-nace-del-silencio/>. Acesso em: 24 jan. 2019.

DIDI-HUBERMAN, Georges. O que vemos, o que nos olha. São Paulo: Editora 34, 1998.

HUNT, Peter. Crítica, teoria e literatura infantil. Cosac Naify, 2010.

JUARROZ, Roberto. Poesia vertical, antologia essencial. Espanha: Catedra, 2001.

LE BRETON, David. El silencio. Madri: Sequitur, 2006.

MELLO, Roger. João por um fio. São Paulo: Companhia das Letrinhas, 2005.

PAZ, Octavio. Los privilégios de la vista I: arte moderno universal. México: Fonfo de Cultura Económica, 1993.

WORNICOV, Ruth et. al. Criança - leitura - livro. São Paulo: Nobel, 1986.

Recebido em 24 de março de 2019.

Aceite em 4 de abril de 2019.

\footnotetext{
'Existe um alfabeto do silêncio / Mas não nos ensinaram a soletra-lo. / Porém, a leitura do silêncio é a única durável, / Talvez mais do que o leitor (tradução nossa).

ii O silêncio nunca é o vazio, mas a respiração entre as palavras, a dobra momentânea que permite o fluir dos significados, o intercâmbio de observações e emoções, o equilíbrio das frases que se amontoam nos lábios e o eco de sua recepção, é o tato que cede ao uso da palavra mediante uma rápida inflexão da voz, explorada de imediato pelo que se espera do momento favorável (tradução nossa).
} 